\title{
An Unusual Prenatal Ultrasound Image of Placental Lake in High Risk Pregnancy
}

\author{
Bursac D, ${ }^{1}$ Kulas T, ${ }^{1}$ Madzarac V, ${ }^{1}$ Kardum V, ${ }^{1}$ Skrtic A, ${ }^{2}$ Hrgovic $Z^{3}$ \\ ${ }^{1}$ Department of Obstetrics and Gynaecology, Merkur University Hospital, Zagreb \\ ${ }^{2}$ Department of Pathology and Cytology, Merkur University Hospital, Zagreb, Croatia \\ ${ }^{3}$ Department of Obstetrics and Gynaecology, University Hospital JW Goethe, Frankfurtam Main, Germany.
}

\section{Dear Editor,}

First sonographic items of placental abnormalities date in late 1970s and early 1980s. ${ }^{1,2}$ They are described as anechoic or hypoechoic lesions, nowadays called "lakes" or "caverns". These anechoic areas are approximately $1 \mathrm{~cm}$ or wider in diameter, surrounded by normal echogenic placental parenchymal. ${ }^{3,4}$ The link between pathological examination and sonographic patterns are intervillous thrombosis, decidualseptal cysts and infarct..-5 Today, some studies that have been done provide the connection between size and number of placental lakes with pregnancy outcome. Our case supports the above presented claim.

We present a case of a 42-year woman at $35+4 / 7$ weeks gestation (G3P2A0) referred to our clinic for regular ultrasound (US) examination. After detailed US examination unusual sonolucent lesions was found. The mother's medical history was significant for a cleft palate without surgical repair, seronegativespondyloarthropathy, Raynaud's syndrome and Hashimoto's thyroiditis, hypothyreosis treated with hormonal supplementation and two prior uncomplicated pregnancies. Mild hypertension was detected in the first trimester and at 17 weeks' gestation, Methyldopa (3x250 mg/day) was prescribed. Early amniocentesis showed a normal male karyotype (46XY). At 33 weeks' gestation she was admitted because of moderate hypertension and contractions recorded on cardiotocography. Dexamethasone (4x6 mg) was given for fetal lung maturation. During hospital stay a routine US exam revealed an unusual sonolucent area $(36 \times 23 \mathrm{~mm})$ \{Figure

\section{CORRESPONDENCE}

\section{Dr Zlatko Hrgovic}

Department of Obstetrics and Gynaecology, University Hospital JW Goethe, Frankfurtam Main, Germany.

Email: info@hrgovic.de

Phone: +49 69293000
$1 \mathrm{~A}\}$ in the placenta and abruption was excluded. Other laboratory findings and clinical examinations were in the reference range for gestational age. At $34^{+3 / 7}$ weeks' gestation she was discharged with antihypertensive therapy, Methyldopa 4x250mg/ day and normal blood pressure. At $35^{+3 / 7}$ weeks' $^{\prime}$ gestation she was admitted to delivery room with regular contractions and preterm premature rupture of membranes. Following admission, US examination was repeated. The diagnosis of an unusual placental lake $(33 \times 27 \mathrm{~mm})$ with hyperechogenic spiral echo and fluctuation of anehogenic liquid inside was confirmed (Figure 1. A, B).

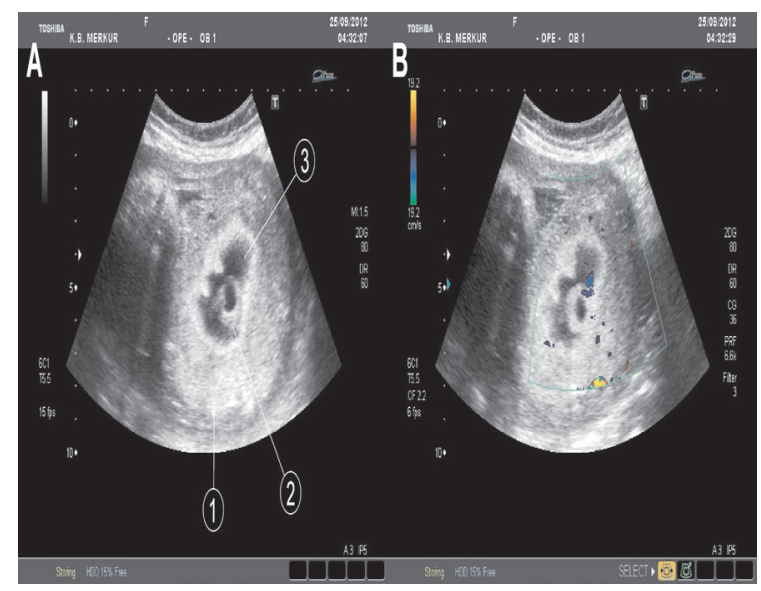

Figure 1. Prenatal 2-dimensional US image using Toshiba, Xario, SSA-660A at $35+3 / 7$ weeks' gestation showing the (A) placental lake (1) with hyperechogenic spiral (2) echo and fluctuation of anehogenic liquid inside (3) (B)and same formation using color Doppler.

The papers in this journal are published under the terms of the Creative Commons Attribution License. Users are allowed to read, download, copy, distribute, print, search, or link to the full texts of the articles in this journal without asking prior permission from the publisher or the author. 
Dinoproston cervical gel was administered for cervical maturation. The delivery was unremarkable. At $35^{+3 / 7}$ weeks' gestation preterm male baby, birthweight and length $2.87 \mathrm{~kg}$ and $49 \mathrm{~cm}\left(75^{\text {th }}\right.$ centile) respectively was born. Apgar score was 9/10 at 1 and 5 minutes after birth.Immediately after birth the child was admitted to the neonatal intensive care unit because of prematurity where he was monitered, clinical examination showed muscle hypotony and later a cranial ultrasound scan revealed II grade intraventricular hemorrhage. The third and fourth stages of labor were unremarkable. According to pathological report placenta measured $20 \times 20 \times 2.5$ $\mathrm{cm}$, weighted 560 grams. A true knot was found in 52-cm-long umbilical cord with central placental insertion. On the cut surface multiple placental lakes were found up to three $\mathrm{cm}$ in diameter $(10 \%$ of placental volume). Morphologic examination of placenta revealed terminal villi showingsyncytial knotting with a focal fibromuscular sclerosis, stromal fibrosis and hypercapillarization $(30 \%, 20 \%$ and $10 \%$ respectively). Chronic villitis was found in the placental lake wall.

Placental lakes are homogenous, anechoic, avillous vascular spaces in the placenta, surrounded by normal echogenic placental parenchyma. ${ }^{6}$ Due to unclear criteria for the diagnosis there has been variation in detection rates from $2.2-17.8 \%$. Two recent studies showed that placental lakes are not associated with uteroplacental complications or an adverse pregnancy outcome. ${ }^{7,8}$ However, multiple placental lakes seen early in pregnancy and in association with decreased umbilical artery blood flow have been associated with fetal growth restriction. ${ }^{9}$ Hwang et al also found that large placental lakes $(>5 \mathrm{~cm})$ were correlated with small-for-gestational-age status. ${ }^{10}$ Our case of an incidental placental lake finding on US was associated with high blood pressure in pregnancy, premature birth and newborn's pathologic brain ultrasound with a clinical correlate. Following literature search and our experience we believe that even incidental placental lake findings might be considered as a significant risk factor in a pregnancy that should be considered as a high risk. For better understanding the correlation between placental lakes and possible complications and outcomes of pregnancies, further researches are needed.

\section{REFERENCES}

1. Fisher CC, Garrett W, Kossof G. Placental aging monitored by gray scale echography. Am J Obstet Gynecol. 1976;124(5):483-8.

2. Cooperberg PL, Wright VJ, Carpenter CW. Ultrasonographic demonstration of a placental maternal lake. J Clin Ultrasound. 1979;7(1):62-4.

3. Harris RD, Simpson WA, Pet LR, Marin-Padilla M, Crow HC. Placental hypoechoic-anechoic areas and infarction: sonographic-pathologic correlation. Radiology. 1990;176(1):75-80.

4. Jauniaux E, Avni FE, Elkhazen N, Wilkin P, Hustin J Morphologic study of ultrasonic placental anomalies in the second half of pregnancy (in French). J Gynecol Obstet Biol Reprod. 1989;18(5):601-13.

5. Spirt BA, Gordon LP, Kagan EH. Intervillous thrombosis: sonographic and pathologic correlation. Radiology. 1983;147(1):197-200.

6. Reis NS, Brizot ML, Schultz R, Nomura RM, Zugaib M. Placental lakes on sonographic examination: correlation with obstetric outcome andpathologic findings. J Clin Ultrasound. 2005;33(2):67-71

7. Thompson MO, Vines SK, A quilina J, Wathen NC, Harrington $\mathrm{K}$. Are placental lakes of any clinical significance? Placenta. 2002;23(8-9): 685-690.

8. Jauniaux E, NicolaidesKH. Placental lakes, absent umbilical artery diastolic flow and poor fetal growth in early pregnancy. Ultrasound Obstet Gynaecol. 1996;7(2):141-4.

9. Hudon L, Belfort MA, Broome DR. Diagnosis and management of placenta percreta: a review. Obstet Gynecol Surv. 1998;53(8):509-17.

10. Hwang HS, Sohn IS, Kwon HS. The clinical significance of large placental lakes. Eur J Obstet Gynecol Reprod Biol. 2012;162(2):139-43 